The 7th international symposium on earthworm ecology $\cdot$ Cardiff $\cdot$ Wales $\cdot 2002$

\title{
Horizontal distribution of an earthworm community at El Molar, Madrid (Spain)
}

\author{
Patrizia Hernández, Mónica Gutiérrez, Marta Ramajo, Dolores Trigo and Dario J. Díaz Cosín* \\ Dpto. Biología Animal I, Facultad de Biología, Universidad Complutense, 28040 Madrid, Spain
}

Submitted September 6, 2002 · Accepted May 14, 2003

\section{Summary}

This paper reports the composition and horizontal distribution of an earthworm community at El Molar (Madrid), and the underlying causes of its distribution. Five species of earthworms were found. The most abundant species were Hormogaster elisae, Allolobophora rosea and Allolobophora caliginosa trapezoides, which showed an aggregate-type distribution. Coarse sand, organic matter and nitrogen appear to be the factors with the greatest influence on $\mathrm{H}$. elisae distribution, whereas porosity and aeration have influence on $A$. c. trapezoides, and clay, organic matter and nitrogen on the presence of $A$. rosea.

Key words: Earthworms, horizontal distribution, soil factors, aggregation

\section{Introduction}

The spatial distribution pattern of organisms is important in biological communities. Three basic patterns exist: random, clumped and uniform (Ludwig \& Reynolds 1988). Generally, soil populations including those of earthworms (Jiménez et al. 2001; Rossi et al. 1997) are distributed in an aggregate (clumped) fashion (Wallwork 1976), a type of distribution that can result from the selective behaviour of the population's members (Jiménez et al. 2001). Several authors have studied the composition and distribution of earthworm communities as well as the influence of interspecific relationships, soil physical and chemical factors on them (Edwards \& Bohlen 1996; Jiménez et al. 2001).

The physical and chemical characteristics of the soil are important in earthworm distribution. Briones et al.
(1995) observed that $\mathrm{pH}$, organic matter and exchangeable cations were the most important factors which establish differences in the ecological behaviour of earthworms. Nordström \& Rundgren (1974) mentioned the importance of organic matter, $\mathrm{pH}$ and moisture in earthworms distribution. Lavelle (1983) indicates the structure of savanna soil animal communities to be influenced by environmental factors, and Mascato et al. (1987) studied the importance of many soil factors in the distribution of several species of earthworms in Galicia (NW Spain).

For several years we have studied the earthworms of El Molar, mainly $H$. elisae and were able to observe the peculiar distribution of the different species in this zone. We found an area where H. elisae was the unique

\footnotetext{
E-mail corresponding author: dadico@bio.ucm.es
} 
earthworm species present, whereas elsewhere it coexisted with some others species. The aim of the present work was to determine the horizontal distribution pattern of earthworm species and the influence of soil physical and chemical characteristics on this pattern.

\section{Materials and Methods}

The dimensions of the experimental plot were $98 \times 83 \mathrm{~m}$. The zone characteristics are recorded in Valle et al. (1997). The vegetation is a subnitrophilic pasture with high percentage of therophytic plants (Valle et al. 1999). This area was divided into 28 subunits of $16 \times 14 \mathrm{~m}$; enough for an initial study. In the bottom right-hand corner of each subunit, an area of $0.5 \mathrm{~m}^{2}$ was cleared of vegetation and earthworms sampled by the manual formalin-separation method. $500 \mathrm{~g}$ of soil were also taken for physical and chemical analysis from the upper left-hand corner of each subunit. A second soil sample was taken, using a core of known weight and volume, to measure soil moisture, porosity and aeration.

The $\mathrm{pH}$ in $\mathrm{H}_{2} \mathrm{O}$, $\mathrm{pH}$ in $\mathrm{KCl}$, soil texture, moisture, porosity and aeration, were determined as described by Guitián \& Carballas (1976). Total nitrogen content was determined by the Kjeldahl method as indicated in Page et al. (1982); organic matter analysis is based in the Anne method (1945).

\section{Statistical Analysis}

The earthworm distribution pattern was studied by using the Morisita index:

$$
I_{\delta}=q \frac{\sum_{\mathrm{i}=1}^{q} n i(n i-1)}{N(N-1)}
$$

where:

- $\mathrm{n}_{\mathrm{i}}(1,2,3, \ldots q)$ is the number of individuals in $q$ samples.
- $\mathrm{N}$ : the total number of individuals.

- $\mathrm{I}_{\delta}<1$ means uniform distribution; $\mathrm{I}_{\delta} \approx 1$ means random distribution, $\mathrm{I}_{\delta}>1$ means aggregate distribution.

Co-occurrence analysis was performed using the CScore index

$$
\sum C U=\sum\left(r_{i}-S\right)\left(r_{j}-S\right)
$$

where $r_{i}$ and $r_{j}$ are the total number of lines in the matrix for species $i$ and $j$, and $S$ is the number of sampling points with both species. High values of this index indicate a tendency of the species to appear separately. The software used for calculations was EcoSim 7.23 .

Principal components analysis (PCA) in combination with a stepwise multiple regression analysis were performed using STATISTICA v.5. 5 software. Distribution maps of the species were made with CORELDRAW 9.0.

\section{Results}

Five earthworm species were found. Hormogaster elisae, Allolobophora caliginosa trapezoides and Allolobophora rosea were the most common, whereas Octodrilus complanatus and Microscolex dubius were occasional (Table 1), less than $5 \%$ of all earthworms collected, and were not included in the statistical analysis.

The Morisita indices $\left(\mathrm{I}_{\delta}\right)$ (Table 1) showed the three most important species to have aggregate distribution $\left(\mathrm{I}_{\delta}>1\right)$. The co-occurrence index $(\mathrm{C}-$ Score $=21.20)$ was significantly $(\mathrm{P}<0.01)$ higher than the mean index expected $(\mathrm{C}-\mathrm{Score}=15.24)$. This showed that segregation of the species was not random.

The studied soils were sandy, poor in organic material and had a pH just less than neutral (Table 2).

Fig. 1 shows the distribution and abundance of $H$. elisae, A. c. trapezoides and A. rosea in the sampled area. $H$. elisae (Fig. 1A) was the most abundant species and was mainly concentrated towards the right

Table 1. Earthworms species, density (ind. $\left./ \mathrm{m}^{2}\right)$, number $(\mathrm{N})$ and biomass (\%). Morisita's index $\left(\mathrm{I}_{\delta}\right)$

\begin{tabular}{lrrrc}
\hline Species & Density & N & Biomass (\%) & Id \\
\hline${ }^{*}$ Hormogaster elisae (He) & 15.36 & 215 & 90.26 & 1.751 \\
${ }^{*}$ Allolobophora caliginosa trapezoides (Ac) & 2.00 & 28 & 3.71 & 6.370 \\
${ }^{*}$ Allolobophora rosea (Ar) & 7.00 & 98 & 5.22 & 3.334 \\
Octodrilus complanatus (Oc) & 0.07 & 1 & 0.79 & ND \\
Microscolex dubius (Md) & 0.29 & 4 & 0.02 & ND \\
\hline
\end{tabular}

ND not determined

* Species used as dependent variables in the stepwise multiple regression analysis. 
Table 2. Means, standard deviation (S.D), maximum and minimum of soil factors at El Molar

\begin{tabular}{lrrrr}
\hline Soil Factors & Mean & S.D. & Max & Min \\
\hline * \% Gravels (GRA) & 32.75 & 6.32 & 43.68 & 17.40 \\
\% Total Sands (SAND) & 67.61 & 7.15 & 80.40 & 53.42 \\
* \% Coarse Sand (COA) & 50.83 & 6.54 & 64.52 & 40.76 \\
* \% Fine Sand (FIN) & 16.78 & 4.02 & 24.03 & 9.43 \\
\% Total Loam (LOA) & 11.84 & 7.49 & 32.23 & 0.90 \\
* \% Coarse Loam (CLO) & 3.69 & 4.38 & 22.61 & 0.25 \\
* \% Fine Loam (FLO) & 8.15 & 4.89 & 16.44 & 0.27 \\
* \% Clay (CLA) & 20.55 & 6.02 & 34.59 & 11.48 \\
* \% Moisture (HUM) & 18.48 & 6.89 & 45.48 & 10.10 \\
* \% Porosity (POR) & 45.68 & 9.64 & 69.45 & 28.72 \\
* \% Aeration (AER) & 27.20 & 9.63 & 55.35 & 10.31 \\
\% Carbon (C) & 1.91 & 0.57 & 2.83 & 0.92 \\
* \% Organic Matter (OM) & 3.29 & 0.99 & 4.88 & 1.60 \\
* \% Nitrogen (N) & 0.16 & 0.05 & 0.24 & 0.08 \\
* C/N ratio (C/N) & 11.75 & 1.13 & 13.66 & 9.19 \\
* pH in H2O (PHH) & 6.42 & 0.30 & 6.97 & 5.89 \\
* pH in KCl (PHK) & 5.51 & 0.34 & 6.24 & 4.90 \\
\hline
\end{tabular}

* Variables used in the PCA
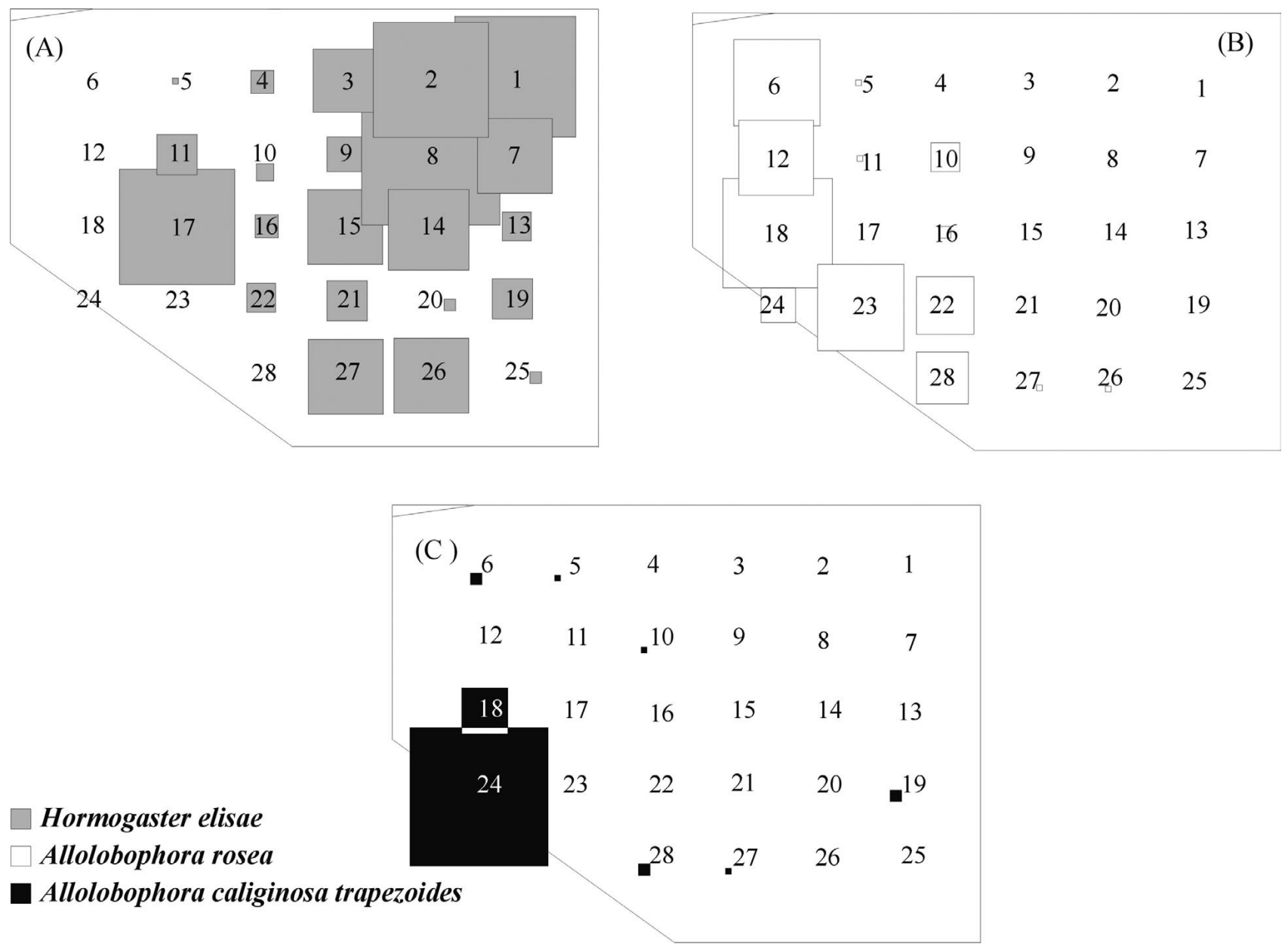

Fig. 1. Distribution and abundance of $H$. elisae $(A)$, A. rosea (B) and $A$. c. trapezoides $(C)$ in the sampled area at El Molar. Each square of $1 \times 1 \mathrm{~mm}$ indicates one individual 
side of the plot, A. rosea was mainly concentrated on the left side (Fig. 1B), and A. c. trapezoides at the lower left (Fig. 1C). The latter was principally accompanied by $A$. rosea.

PCA was performed with the variables marked in Table 2. The first five axes account for $81.78 \%$ of variability. The first axis showed a negative correlation with $\mathrm{pH}$ and fine sand, and positive with $\mathrm{C} / \mathrm{N}$ ratio. The second axis was positively correlated with organic matter and nitrogen, but negatively correlated with coarse sand. The third axis was defined by gravels and moisture, the fourth showed a negative correlation with porosity and aeration and the fifth with clay (Table 3).

We used a stepwise multiple regression analysis (Table 4) in order to examine the relationships between the abundance of each species (dependent variable) with the PC-scores (independent variables), which re-

Table 3. Principal components analysis with the edafic variables within the twenty-eight samples

\begin{tabular}{lrrrrr}
\hline${ }^{*}$ Variables & \multicolumn{1}{c}{ Axis 1 } & \multicolumn{1}{c}{ Axis 2 } & Axis 3 & \multicolumn{1}{c}{ Axis 4 } & \multicolumn{1}{c}{ Axis 5 } \\
\hline OM & 0.1550 & $\mathbf{0 . 9 2 6 5}$ & 0.0711 & -0.0946 & 0.0490 \\
$\mathbf{N}$ & -0.0839 & $\mathbf{0 . 9 4 1 0}$ & 0.0566 & 0.0068 & -0.0011 \\
C/N & $\mathbf{0 . 7 7 8 9}$ & 0.0796 & 0.0863 & -0.3020 & 0.0909 \\
PHH & $\mathbf{- 0 . 8 5 1 4}$ & 0.1853 & 0.2004 & 0.2411 & -0.2027 \\
PHK & $-\mathbf{0 . 7 7 9 6}$ & 0.4215 & 0.1602 & 0.0917 & -0.1624 \\
HUM & -0.1245 & 0.0165 & $\mathbf{0 . 8 5 7 8}$ & -0.1530 & 0.0771 \\
POR & 0.1363 & -0.0373 & 0.1737 & -0.9277 & 0.0576 \\
AER & 0.2242 & -0.0490 & -0.4278 & -0.8240 & 0.0037 \\
COA & 0.2998 & $-\mathbf{0 . 7 6 1 4}$ & 0.0940 & -0.2419 & 0.2051 \\
FIN & $-\mathbf{0 . 8 2 8 2}$ & -0.2044 & -0.0971 & -0.1073 & -0.0844 \\
CLO & 0.3862 & 0.4245 & -0.3863 & 0.2791 & 0.1771 \\
FLO & 0.2108 & 0.5392 & 0.1402 & 0.0525 & 0.6942 \\
CLA & -0.2336 & 0.2518 & 0.1408 & 0.0971 & $-\mathbf{0 . 8 8 6 1}$ \\
GRA & 0.1406 & 0.0659 & $\mathbf{0 . 7 3 9 6}$ & 0.3115 & -0.1345 \\
Eigenvalues & 4.0319 & 3.0678 & 1.6994 & 1.6083 & 1.0420 \\
\% variance & 28.7997 & 21.9130 & 12.1389 & 11.4883 & 7.4428 \\
\hline
\end{tabular}

Emboldened values indicate correlations of original variables with the axes bigger than 0.7000 .

* Abbreviations as Table 2

Table 4. Models obtained by stepwise multiple regression analysis between abundances of species $[$ H. elisae (He), A. c. trapezoides (Ac) and A. rosea (Ar)] and PC-scores

\begin{tabular}{|c|c|c|c|c|}
\hline & $\beta$ & S.E & $t(23)$ & p-level \\
\hline \multicolumn{5}{|c|}{ Dependent variable: He } \\
\hline AXIS 2 & -0.52 & 0.16 & -3.30 & 0.003 \\
\hline AXIS 5 & 0.30 & 0.16 & 1.93 & 0.066 \\
\hline AXIS 3 & -0.28 & 0.16 & -1.77 & 0.089 \\
\hline \multicolumn{5}{|c|}{ Dependent variable: Ac } \\
\hline Intercpt & & & 2.44 & 0.023 \\
\hline AXIS 4 & -0.39 & 0.17 & 2.33 & 0.029 \\
\hline AXIS 2 & 0.32 & 0.17 & 1.91 & 0.069 \\
\hline AXIS 5 & -0.24 & 0.17 & -1.44 & 0.163 \\
\hline AXIS 3 & -0.23 & 0.17 & -1.35 & 0.190 \\
\hline \multicolumn{5}{|c|}{ Dependent variable: Ar } \\
\hline Intercpt & & & 3.96 & 0.000 \\
\hline AXIS 5 & -0.61 & 0.15 & -4.15 & 0.000 \\
\hline AXIS 2 & 0.34 & 0.15 & 2.32 & 0.029 \\
\hline
\end{tabular}

Standardised regression coefficients ( $\beta$ ), standard errors (S.E), results from t-tests $[t(d . f)]$ and associated probability ( $p$ ) levels 
flect edaphic characteristics of the twenty-eight samples. The model with the abundance of $H$. elisae as the dependent variable $\left(\mathrm{F}_{(3,23)}=5.92, \mathrm{P}=0.004\right)$, showed a negative correlation between this species and axis 2 , thus $H$. elisae was more abundant in places where the soil had more coarse sand and low organic matter and nitrogen. A similar analysis with the abundance of $A$. $c$. trapezoides as dependent variable $\left(\mathrm{R}^{2}=0.37, \mathrm{~F}_{(4,22)}=\right.$ $3.25, \mathrm{P}=0.031$ ) showed a negative correlation between this species and axis 4, this indicated that $A$. $c$. trapezoides was more abundant in places with high porosity and aeration. The model with $A$. rosea $\left(\mathrm{F}_{(2,24)}=\right.$ 11.31, $\mathrm{P}<0.001)$ showed a significative and negative correlation with axis 5 and positive with axis 2 . Therefore $A$. rosea was found in soils with high clay, organic matter and nitrogen levels.

\section{Discussion}

Soil animal populations usually show clumped distributions (Wallwork 1976). This is clearly the case of earthworms in El Molar and agrees with that observed by Jiménez et al. (2001) in acid-soil savannas in the eastern plains of Colombia. This aggregation could be due to soil factors, biological factors such as intra- and interspecific competition, or a combination of both.

We observed a strong relationship between $A$. rosea and high content of clay. Briones et al. (1995) mentioned an association between clay-silty soils and $A$. rosea and Nordström \& Rundgren (1974) observed a relationship between soil clay content and total abundance of earthworms, especially A. rosea, A. c. trapezoids, A. longa and Lumbricus terrestris in Sweden. However, this relationship might be secondary, since soil clay content is also correlated with factors such as water holding capacity and cationic exchange capacity, which directly influences earthworm abundance. It is possible that water is better retained in the most clayrich parts of the sampled area, and that there is less washing out of organic material. This would favour the presence of polyhumic species such as A. rosea.

In this study we observed a relationship between $A$. c. trapezoides and aeration and porosity; Briones et al. (1995) observed that aeration affected the distribution of A. c. trapezoides and porosity that of A. c. caliginosa in Northwest Spain.

H. elisae appears better adapted to soils poor in organic matter and nitrogen and high content of coarse sand. It normally appeared alone but was found in some places with $A$. c. trapezoides and A. rosea. Both commonly appear together (Edwards \& Bohlen 1996).

Coarse sand appears to have a strong influence on the presence of $H$. elisae at El Molar. This agrees with that reported by Lee (1985), who indicates that soil abrasiveness and susceptibility to drought affect earthworm populations. Soil moisture is known to be important to earthworms (Nordström \& Rundgren 1974; Lee 1985). It is possible $H$. elisae can survive in this kind of soil, with high coarse sand content and able to retain a small amount of water, because it can enter paradiapause below a certain soil humidity, Ruiz (unpublished data).

Environmental factors are not alone in determining the distribution of earthworms. Some authors (González et al. 1999) observed that plant species composition could produce differences in earthworm abundance and distribution in tropical wet forests. Nuutinen et al. (1998) mentioned the disjunct distribution of Lumbricus terrestris and Dendrobaena rubidus in a field in East Finland, could be due to competitive interaction. This agrees with that observed by other authors that indicate relationship between species plays a basic role in the structure of natural communities (Lavelle 1983; Albrecht \& Gotelli 2001; Garvín et al. 2002). The high co-occurrence indices recorded for $\mathrm{El}$ Molar plot might suggest that competition affects the structure of this community. Gotelli (2000) concluded that communities structured in this way have higher values of co-occurrence index than those randomly structured. Further research is needed to fully determine the importance of environmental factors, competition, food selection and resource use by the different species in order to better understand their distribution criteria.

Acknowledgements. The authors thank Dr. José A. Díaz, Dr. Juan B. Jesús, Pilar Ruiz, Rubén Gil and Aitor Luis for their collaboration. This study was financially supported by the Spanish Ministry of Science and Technology (Project BOS 2001-1963).

\section{References}

Albrecht, M., Gotelli, N. J. (2001) Spatial and temporal niche partitioning in grassland ants. Oecologia 126, 134-141.

Anne, P. (1945) Sur le dosage rapide du carbone organique des sols. Annales de Agronomie 2, 162-172.

Briones, M. J. I., Mascato, R., Mato, S. (1995) Autecological study of some earthworm species (Oligochaeta) by means of ecological profiles. Pedobiologia 39, 97-106.

Edwards, C. A., Bohlen, P. J. (1996) Biology and Ecology of Earthworms. Third edition. Chapman \& Hall, London, 426 pp.

Garvín, M.H.,; Trigo, D., Hernández, P., Ruiz, M.P., Díaz Cosín, D. J. (2002) Interactions of Hormogaster elisae (Oligochaeta, Hormogastridae) with other earthworm species from Redueña (Madrid, Spain). Applied Soil Ecology 20, 163-169. 
González, G., Zou, Z., Sabat, A., Fetcher, N. (1999) Earthworm abundance and distribution pattern in contrasting plant communities within a tropical wet forest in Puerto Rico. Caribbean Journal of Science 35, 93-100.

Gotelli, N. J. (2000) Null model analysis of species co-occurrence patterns. Ecology, 81, 2606-2621.

Guitián, F., Carballas, T. (1976) Técnicas de análisis de suelos. Segunda edición. Editorial Pico Sacro, Santiago de Compostela, $288 \mathrm{pp}$.

Jiménez, J. J., Rossi, J. P., Lavelle, P. (2001) Spatial distribution of earthworms in acid-soil savannas of the eastern plains of Colombia. Applied Soil Ecology 17, 267-278.

Lavelle, P. (1983) The soil fauna of tropical savannas. I. The community structure. In: Bourlière, F. (ed) Tropical Savannas. Elsevier Scientific Publishing Company, Amsterdam, pp. 477-484.

Lee, K.E. (1985) Earthworms: ecology and relationships with soils and land use. Academic Press, Sydney, 411 pp.

Ludwig, J. A., Reynolds, J.F. (1988) Statistical ecology: A primer on methods and computing. John Wiley \& Son, Inc., New York, 337 pp.

Mascato, R. F., Mato, S., Trigo, D., Mariño, F., Díaz Cosín, D. J. (1987) Factores del suelo y distribución de las lombrices de tierra en dos zonas de Galicia: Comparación de diferentes métodos estadísticos. Revue d'Écologie et de Biologie du Sol 24, 111-135.
Nordström, S., Rundgren, S. (1974) Environmental factors and lumbricid associations in southern Sweden. Pedobiologia 14, 1-27.

Nuutinen, V., Pitkänen, J., Kuusela, E., Widbom, T., Lohilahti, H. (1998) Spatial variation of an earthworm community related to soil properties and yield in a grassclover field. Applied Soil Ecology 8, 85-94.

Page, A. L., Miller, R. H., Keeney, D. R. (1982) Methods in Soil Analysis. Part 2: Chemical and Microbiological Properties. Agronomy 9, ASA-SSSA, Madison. Wisconsin. USA.

Rossi, J. P., Lavelle, P., Albrecht, A. (1997) Relationships between spatial pattern of the endogeic earthworm Polypheretima elongata and soil heterogeneity. Soil Biology and Biochemistry 29, 485-488.

Valle, J. V., Moro, R. P., Garvín, M. H., Trigo, D., Díaz Cosín, D. J. (1997) Annual dynamics of the earthworm Hormogaster elisae (Oligochaeta, Hormogastridae) at El Molar. (Madrid, Spain). Soil Biology \& Biochemistry 29, 309-312.

Valle, J. V., Garvín, M. H., Trigo, D., Martínez, F., Belinchón, C., Díaz Cosín, D. J. (1999) Vertical distribution of Hormogaster elisae (Oligochaeta, Hormogastridae) in soil at El Molar (Central Spain). Pedobiologia 43, 1-7.

Wallwork, J. A. (1976) The distribution and diversity of soil fauna. Academic Press, London, 355 pp. 